\title{
Racionalidad a diario: neumonía
}

The everyday rationality: pneumonia

La aparición de cada nueva vacuna abre la expectativa de poder al menos controlar un problema de salud. Sin embargo, los problemas de salud pueden ser más complejos y muchas veces la sociedad y aun los profesionales pueden colaborar inadvertidamente en su vigencia.

A pesar del impacto que la introducción de la vacunación masiva contra el neumococo en 2000 en Estados Unidos pueda haber tenido en la tasa de hospitalización por neumonía y en la incidencia de complicaciones en ese país, ${ }^{1}$ parece que su impacto sobre el número de consultas por la misma enfermedad no ha sido de la misma magnitud. Un reciente artículo estima que la tasa de consultas ambulatorias pediátricas por neumonía adquirida en la comunidad no se modificó significativamente entre $1994(19,2 / 1000)$ y 2007 $(22,4 / 1000){ }^{2}$

Pero más interesante aún es la investigación que hacen los autores sobre el uso de antibióticos en estos pacientes, encontrando que en cerca del $80 \%$ de los que recibían antibióticos se trataba de un antibiótico de espectro inadecuado (macrólidos o cefalosporinas) o de amplio espectro (amoxicilina-clavulanato), en lugar de penicilina (o amoxicilina). Además, ellos encontraron que este fenómeno se asociaba al incremento en la edad de los pacientes y a la atención en consultorio en relación a los asistidos en hospitales. Entre las especulaciones que podrían explicar sus hallazgos, los autores incluyen la preocupación de los médicos por la presencia de microorganismos mal llamados "atípicos", ${ }^{3}$ a pesar de que no se ha demostrado en forma conclusiva la eficacia de macrólidos contra Mycoplasma pneumoniae. ${ }^{4}$ También podría influir la mayor exposición de los médicos en consultorios a la propaganda médica, más centrada en antibióticos de amplio espectro.

Este tema debe llamar la atención sobre una parte importante de nuestra práctica profesional, ya que las infecciones respiratorias agudas (y la neumonía dentro de ellas) son la primera causa de consulta en pediatría. Debido a ello, el uso inadecuado de antibióticos en esta condición alcanza una dimensión muy significativa.

A pesar que el vocablo neumonía despierta en todo el que lo oye, tanto público como profesionales, una sensación de "enfermedad que requiere antibióticos", debe tenerse siempre presente que cerca de la mitad de las neumonías son de etio- logía viral. ${ }^{5}$ Como muestra contundente de esta realidad valga el estudio de Hazir y col., quienes compararon la eficacia de amoxicilina contra placebo en menores de 6 años con diagnóstico de neumonía. ${ }^{6}$ No debe sorprendernos que ellos encontraran que la respuesta al tratamiento no difería entre ambos grupos.

El uso de terminología inapropiada ("neumonitis", "neumonía atípica")7 y el empleo de algoritmos diagnósticos muy simples de los que se desprende que todo paciente con diagnóstico de neumonía debe recibir antibióticos pueden conspirar contra un uso más adecuado de antibióticos. ${ }^{8}$

Todos los días debemos apelar al mejor criterio de nuestros pediatras para conseguir un uso más adecuado de los antibióticos, recordando que ello no sólo implica usarlos cuando se sospeche patología bacteriana sino, cuando corresponda, recurrir a antimicrobianos con un espectro enfocado hacia el microorganismo cuya presencia se sospeche. Debemos recordar que su uso inapropiado expone innecesariamente a efectos adversos, incrementa los costos de la salud y favorece el desarrollo de resistencia bacteriana a estas drogas.

Es fundamental la contribución que cada uno de nosotros puede hacer a un uso adecuado de antibióticos.

\section{Dr. Fernando Ferrero \\ Docencia e Investigación Hospital General de Niños Pedro de Elizalde Buenos Aires}

1. Grijalva CG, Nuorti JP, Arbogast PG, Martin SW, et al. Decline in pneumonia admissions after routine childhood immunisation with pneumococcal conjugate vaccine in the USA: a time-series analysis. Lancet 2007;369(9568):1179-86.

2. Kronman MP, Hersh AL, Feng R, Huang YS, Lee GE, Shah SS. Ambulatory visit rates and antibiotic prescribing for children with pneumonia, 1994-2007. Pediatrics 2011; 127(3):411-8.

3. Murdoch D, Chambers S. Atypical pneumonia-time to breathe new life into a useful term? Lancet Infect Dis 2009; 9: 512-19.

4. Gavranich JB, Chang AB. Antibiotics for community acquired lower respiratory tract infections (LRTI) secondary to Mycoplasma pneumoniae in children. Cochrane Database Syst Rev 2010;(7):CD004875.

5. Ruuskanen O, Lahti E, Jennings LC, Murdoch DR. Viral pneumonia. Lancet 2011; 377(9773):1264-75. 
6. Hazir T, Nisar YB, Abbasi S, Ashraf YP, et al. Comparison of oral amoxicillin with placebo for the treatment of world health organization-defined nonsevere pneumonia in children aged 2-59 months: a multicenter, double-blind, randomized, placebo-controlled trial in Pakistan. Clin Infect Dis 2011; 52(3):293-300.
7. González Pena H, Ferrero F. El difícil diagnóstico de la simple neumonía. Arch Argent Pediatr 2009;107(6):483-4.

8. Shah S, Bachur R, Kim D, Neuman M. Lack of predictive value of tachypnea in the diagnosis of pneumonia in children. Pediatr Infect Dis J 2010; 29(5): 406-409.

\section{El desafiante mundo del recién nacido normal}

\section{The challenging world of the normal newborn}

La atención del recién nacido normal se puede enfocar desde distintos puntos de vista.

En primer término pareciera lógico que los recién nacidos sean atendidos por médicos neonatólogos, es decir, aquellos que eligieron esta especialidad y se capacitaron para brindar al recién nacido y su familia la mejor atención. Y acá tenemos la primera dificultad: los médicos neonatólogos parecen ser una especie en extinción. Las plazas disponibles en la Residencia de Neonatología no llegan a cubrirse, muchos servicios no pueden completar sus planteles de médicos de guardia de Neonatología. ${ }^{1}$ Algunos han debido cerrarse luego de derivar a sus pacientes. En Europa, un informe técnico sobre la provisión de servicios neonatales, define a la madre y la familia ampliada como los responsables principales de la atención del recién nacido normal, con el apoyo de la obstétrica, la enfermera neonatal o el pediatra. Los escasos neonatólogos disponibles atienden a los recién nacidos de mayor complejidad en las Unidades de Cuidado Intensivo Neonatal. En algunos servicios de maternidad, enfermeras especialmente capacitadas en los cuidados neonatales ocupan el lugar de los médicos neonatólogos faltantes. ${ }^{2}$ Pero también se menciona que el número de profesionales de enfermería no es suficiente, realidad que afecta a todos los países.

La atención neonatal tiene un peso relevante en la salud materno-infantil. Cuando se consideran las cifras de mortalidad infantil se ve que de los 745336 niños nacidos en 2009 en Argentina, murieron 9026 durante el primer año de vida.

El 47\% de estos niños murieron en la primera semana de vida, y un $18 \%$ más, en el resto del primer mes. O sea que casi la mitad de la mortalidad infantil ocurre en los primeros días de vida y más de la mitad durante el primer mes. Según la Dirección de Estadísticas e Información en Salud del Ministerio de Salud de la Nación, el 55\% se debe a causas reducibles por diagnóstico y tratamiento oportuno. ${ }^{3}$

Decididamente para disminuir la mortalidad infantil se requiere mejorar la atención neonatal.

¿Por qué entonces los profesionales de la salud no acuden a este llamado de la lógica?

Pareciera que la sociedad moderna se autodestruye. Así como necesita en forma urgente de profesionales capacitados para la atención de los recién nacidos, ha encontrado en este terreno negocios muy interesantes para explotar. Por un lado, profesionales exigidos por la urgencia, con alto nivel de estrés, y la responsabilidad de los minutos de oro que decidirán la vida y la calidad de vida futura. Por otro lado un sistema de salud que no reconoce estos esfuerzos y una industria de la mala praxis alimentándose de la enorme fragilidad de los recién nacidos y la mayor vulnerabilidad de los que los atienden. ${ }^{4}$ Hay que buscar una salida a esta situación.

En segundo término habría que plantear quién se ocupa de los recién nacidos normales, tanto desde el punto de vista asistencial como de la docencia e investigación.

Los neonatólogos, cuando los hay, capacitados en la alta complejidad de las terapias intensivas neonatales, pueden encontrar menos apasionante, diríamos "rutinaria", la atención de la familia con un recién nacido normal, de bajo o mediano riesgo. Pero ¿qué quiere decir bajo o mediano riesgo? En términos habituales señala el riesgo de enfermar gravemente y requerir atención de alta complejidad.

En esta definición se olvida otro riesgo, que es perder la oportunidad de sobrevivir y tener una calidad de vida mejor, por muchos años. Se sabe que las intervenciones médicas tienen mayor impacto cuanto más tempranamente ocurren.

Estos recién nacidos normales constituyen el 90\% aproximadamente de los nacimientos. En los 
primeros días de vida se cultiva el vínculo padreshijo, cuya ausencia o debilidad se acompaña de maltrato, abandono y violencia.

También se determina el tipo de alimentación que recibirán. La lactancia materna mejora el coeficiente intelectual, favorece la inmunidad, reduce las expresiones alérgicas, disminuye el riesgo de obesidad, hipercolesterolemia, diabetes e hipertensión. La etapa más importante para lograr la mejor lactancia (la posible para cada familia), son los primeros días de vida.

En el período neonatal se inculcan las pautas de prevención de la muerte súbita del lactante. Los hábitos relacionados con el cuidado de la vida del niño durante su primer año deben instalarse antes del egreso de la maternidad.

Además, hay enfermedades inaparentes al momento del nacimiento que exigen del profesional de la salud conocerlas, pensarlas, detectarlas y actuar rápidamente para evitar el daño futuro. Como se ve, lejos de ser una actividad rutinaria, requiere la inmensa creatividad de construir en el breve tiempo de una consulta, la mejor atención para cada familia en particular. Saber mucho, elegir lo que se transmite, hablar lo necesario. Un verdadero arte.

Desde el punto de vista de la docencia y la investigación, los temas del recién nacido de bajo y mediano riesgo son un desafío al espíritu científico. Hay muchas preguntas sin contestar porque la Neonatología es una disciplina relativamente reciente y la atención neonatal se va construyen- do día a día. Y también hay muchas preguntas sin hacer, porque se asume que lo que se hizo siempre así, no tiene por qué cambiar. La investigación en este campo no requiere altos costos y sus resultados se aplican a la mayoría de los recién nacidos.

Como vemos, hay materia de pensamiento y acción para muchos: responsables de políticas de salud, organizaciones profesionales, profesionales relacionados a la salud materno-infantil, equipos de investigación, docentes. ${ }^{5}$ Hay mucho por hacer y el tiempo apremia.

Dra. Norma E. Rossato Editora Asociada Archivos Argentinos de Pediatría

1. Longo D. Residencias médicas. Editorial. Noticias Metropolitanas. Sociedad Argentina de Pediatría. Marzo de 2007. [Acceso 2 de julio de 2011]. Disponible en: www.sap.org.ar / staticfiles/organizacion/38.pdf.

2. Hallsworth M, Farrands A, Oortwijn WJ, Hatziandreu E. The provision of neonatal services. Technical reportfor the National Audit Office. [Acceso 2 de julio de 2011]. Disponible en: www. nao.org.uk/idoc.ashx?docId=5a5f4c15-6d2a-4ecd-a2bf...1.

3. Dirección de Estadísticas e Información en Salud. Anuario 2009. [Acceso 26 de junio de 2011]. Disponible en: http:// www.deis.gov.ar/Publicaciones/Archivos/Serie5Nro53.pdf.

4. Halac E, Moya MP, Olmas JM. Cada vez menos neonatólogos: ¿crónica de una muerte anunciada? Carta al editor. Arch Argent Pediatr 2008;106(5):477-9.

5. Ceriani Cernadas JM. Participación de los médicos asistenciales en las deficiencias sanitarias y en el cuidado de la salud en nuestro país. Editorial. Arch Argent Pediatr 2011;109(2):98-9. 